\title{
Basic research on mechanism of $\mathrm{BN}$ inclusion in improving the machinability of steel
}

\author{
Chen Ya-nan ${ }^{\mathrm{a}}$, Bao Yan-ping ${ }^{\mathrm{a}, \bowtie}$, Wang Min ${ }^{\mathrm{b}}$, Cai Xiao-feng, ${ }^{\mathrm{a}}$, Wang Lin-jing ${ }^{\mathrm{a}}$, Zhao Li-hua ${ }^{\mathrm{a}}$ \\ ${ }^{a}$ State Key Laboratory of Advanced Metallurgy, University of Science and Technology \\ Beijing, 30 Xueyuan Road, Haidian District, Beijing 100083, P. R. China \\ ${ }^{b}$ National Engineering Research Center of Flat Rolling Equipment, University of Science and \\ Technology Beijing, 30 Xueyuan Road, Haidian District, Beijing 100083, P. R. China \\ Corresponding author: baoyp@ustb.edu.cn
}

Submitted: 18 March 2014; Accepted: 8 August 2014; Available On-line: 13 November 2014

\begin{abstract}
Boron nitride-added eco-friendly free cutting steel has recently drawn more and more attention. But, the mechanisms explaining the role of $\mathrm{BN}$ inclusions improving the machinability of steels is not very clear. In this investigation, the material removal mechanism for cutting of $\mathrm{BN}$ inclusions in steels is explored, using a combination of theoretical analysis and a series of experiments. First, the actual shape of BN inclusions is observed and the amount and distribution of BN inclusions is quantitatively analyzed. Subsequently, the cutting performance of the steel is determined by cutting experimental tests. Moreover, the micro mechanical properties and the material removal mechanisms for cutting of $\mathrm{BN}$ inclusions are investigated by means of nanoindentation. The results revealed that the $\mathrm{BN}$ inclusions are hexagonal and are uniformly distributed, their average content is 23.2 per unit area and their volume fraction is $0.51 \%$ in the steel with $74 \mathrm{ppm} \mathrm{B}$ and $180 \mathrm{ppm} \mathrm{N}$. It is shown that $\mathrm{BN}$ inclusions can improve the cutting performance of steel significantly, and a model describing the material removal mechanism for cutting of $\mathrm{BN}$ inclusions is proposed. $\mathrm{BN}$ inclusions act as stress concentration source, lubrication and wrappage of hard particles.
\end{abstract}

KEYWORDS: Boron Nitride (BN); Cutting mechanism; Free cutting steel; Inclusion; Machinability

Citation / Cómo citar este artículo: Yanan, Ch., Yan-ping, B., Min, W., Xiao-feng, C., Lin-jing, W., Li-hua, Z. (2014) "Basic research on mechanism of BN inclusion in improving the machinability of steel". Rev. Metal. 50(4): e028. doi: http://dx.doi.org/10.3989/revmetalm.028.

RESUMEN: Investigación básica sobre los mecanismos que explican el papel de las inclusiones de BN en la mejora de la maquinabilidad de aceros. Los aceros de fácil mecanizado o corte libre con nitruro de boro agregado han despertado un gran interés. Sin embargo, aún no se han determinado los mecanismos que explican el papel de las inclusiones de $\mathrm{BN}$ en la mejora de la maquinabilidad de estos aceros. En este trabajo, se investigan los mecanismos de corte de las inclusiones BN en aceros mediante la combinación de un análisis teórico y una serie de experimentos. En primer lugar, se determina la morfología de las inclusiones BN y se analiza cuantitativamente la cantidad y distribución de las mismas. Posteriormente, el rendimiento de corte del acero se determina mediante ensayos de corte. Por otra parte, las propiedades mecánicas locales y los mecanismos de eliminación de material para el corte de inclusiones BN son investigados por medio de nanoindentación. Los resultados revelaron que las inclusiones son $\mathrm{BN}$ con forma hexagonal y se distribuyen de manera uniforme, su contenido promedio es de 23,2 por unidad de superficie y su fracción de volumen es $0,51 \%$ en el acero con un contenido de 74 ppm de B y 180 ppm N. Se demuestra que las inclusiones $\mathrm{BN}$ pueden mejorar el rendimiento de corte del acero de manera significativa, y se presenta un modelo que describe el mecanismo de corte de las inclusiones de BN. Finalmente, se comprueba que los $\mathrm{BN}$ actúan como fuente de concentración de tensiones, la lubricante y de conglomerante de partículas duras.

PALABRAS CLAVE: Nitruros de boro (BN); Mecanismo de corte; Acero de corte libre; Inclusión; Maquinabilidad

Copyright: (C) 2014 CSIC. This is an open-access article distributed under the terms of the Creative Commons Attribution-Non Commercial (by-nc) Spain 3.0 License. 


\section{INTRODUCTION}

As an important material for national economy, free cutting steel is very useful for machining, household appliance and automobile. At present, free cutting steel is mainly divided into two categories: lead series and sulfur series (Yoshimura, 1985; Katayama et al., 1988). Non-metal elements added deliberately in those series which can decrease steel quality, pollute the environment and cause serious injuries to the health of operators (Liu and Chen, 2014; Spitzig and Sober, 1981; Yamamoto et al., 2011; Chen et al., 2007; Spitzig, 1983). Thereby it is urgently required to develop a new generation of environment-friendly free cutting steel and make innovations on cutting mechanisms. BN free cutting steel, as an important new free cutting steel, has drawn more and more attention because of its advantages in environmental protection and good mechanical properties.

In recent years, the possibility of adding $\mathrm{BN}$ to improve the machinability of steel was explored (Tanaka et al., 2007; Tanaka et al., 2009). The influences of steel composition and tool material on the machinability have been investigated and confirmed that $\mathrm{BN}$ inclusions could improve the machinability of steel significantly. The precipitation behavior of $\mathrm{BN}$ type inclusions in steel was studied and the relationship between the size, distribution of $\mathrm{BN}$ inclusions and the cooling rate of the steel was explored (Wang et al., 2013a; Wang et al., 2013b). Then a control model of $\mathrm{BN}$ inclusions was proposed (Wang et al., 2013c). The influence of heat treatment on formation behavior of boron nitride inclusions in heat resistant steel was discussed (Sakuraya et al., 2006). Besides, BN free-cutting stainless steel for precision machining capable of attaining all of excellent cutting accuracy, machinability, corrosion resistance, and environmental friendliness at the same time was developed successfully by the method of heat treatment (Emura et al., 2012; Emura et al., 2013). In order to optimize cutting performance of $\mathrm{BN}$ added steel, cutting mechanism of $\mathrm{BN}$ inclusions is required to be investigated. In this paper, different modes and materials of cutting are chosen to investigate the cutting mechanism of $\mathrm{BN}$ inclusions. By combination with nanoindentation, the cutting mechanism model of $\mathrm{BN}$ inclusions is proposed. Owing to the great wealth of BN-type environmentfriendly free cutting steel applications, the study will have significant practical implication.

\section{EXPERIMENT}

The samples were obtained by crucible melting and the experiments were proceeded in vacuum induction furnace. A crucible with a capacity of $200 \mathrm{~kg}$ was used. The whole process of the experiments was carried out with argon protection. The industrial pure iron was adopted as the basic material in the experiment. Ferro boron (boron content is $20 \mathrm{wt} \%$ ) and $\mathrm{MnN}$ (purity is $99.99 \%$ ) were added into steel to obtain B and N. The influence of free B on the hardenability of the steel could be eliminated for the N/B ratio in steel higher than 1.7, so N/B ratio is controlled higher than 1.7 in the research. The chemical composition of the samples obtained by crucible melting is shown in Table 1 .

Cutting experiments were performed to investigate the machinability of different samples. Experimental materials were BN free cutting steel sample and comparison sample. Experimental conditions are shown in Table 2. Experimental processes were shown as follows: high-speed drills were used to cut experimental materials, and cutting was interrupted to measure the average width of flank wear by an optical microscope. To obtain a statistically valid conclusion, each sample undertook three tests and the average value were adopted.

In order to obtain the original $\mathrm{BN}$ inclusions in steel without loss, the samples were electrolyzed by organic electrolyte solution (Bao et al., 2012) (methanol: triethanolamine: tetramethylammonium chloride is $71: 11: 2$ by mass ratio) and the inclusions were extracted by high-speed centrifuge (TG-16) and glass capillary (inside diameter is $1 \mathrm{~mm}$ ) after electrolysis. The rotation speed was set to $9000 \mathrm{r} \mathrm{min}^{-1}$ and the centrifugal time was set to 3 minutes.

Nanoindentation method is used to investigate the micro mechanical properties of the matrix and the inclusions in steel, including $\mathrm{BN}, \mathrm{MnS}, \mathrm{Al}_{2} \mathrm{O}_{3}$ and TiN, so that the effect of $\mathrm{BN}$ inclusion on improving machinability of steel can be explored further.

\section{RESULTS AND DISCUSSION}

\subsection{The morphology of $\mathrm{BN}$ inclusions}

The analysis results of the $\mathrm{BN}$ inclusion in experimental samples which extracted by electrolysis shows that $\mathrm{BN}$ is cluster-like inclusion,

TABlE 1. Chemical compositions (in mass pct) of casted samples

\begin{tabular}{lcclccccccccc}
\hline \multicolumn{1}{c}{ Sample } & $\mathbf{C}$ & $\mathbf{S i}$ & $\mathbf{M n}$ & $\mathbf{S}$ & $\mathbf{P}$ & $\mathbf{C r}$ & $\mathbf{N i}$ & $\mathbf{C u}$ & $\mathbf{B}$ & $\mathbf{N}$ & $\mathbf{O}$ & $\mathbf{A l}$ \\
\hline C45 & 0.42 & 0.25 & 1.0 & 0.0126 & 0.017 & 0.026 & 0.024 & 0.020 & 0.0005 & 0.018 & 0.0015 & 0.0002 \\
C45BN & 0.45 & 0.30 & 1.07 & 0.0120 & 0.019 & 0.022 & 0.012 & 0.020 & 0.0074 & 0.018 & 0.0014 & 0.004 \\
\hline
\end{tabular}


TABLE 2. Cutting experiment conditions

\begin{tabular}{lc}
\hline \multicolumn{1}{c}{ Tool } & $\begin{array}{c}\text { Bench drilling machine(LT-13), Optical } \\
\text { microscope, High-speed drill }\end{array}$ \\
\hline Rotational speed & $560 \mathrm{r} \cdot \mathrm{min}^{-1} / 2100 \mathrm{r} \cdot \mathrm{min}^{-1}$ \\
Feed method & Manual feed \\
Coolant & Dry \\
Cutting mode & Via
\end{tabular}

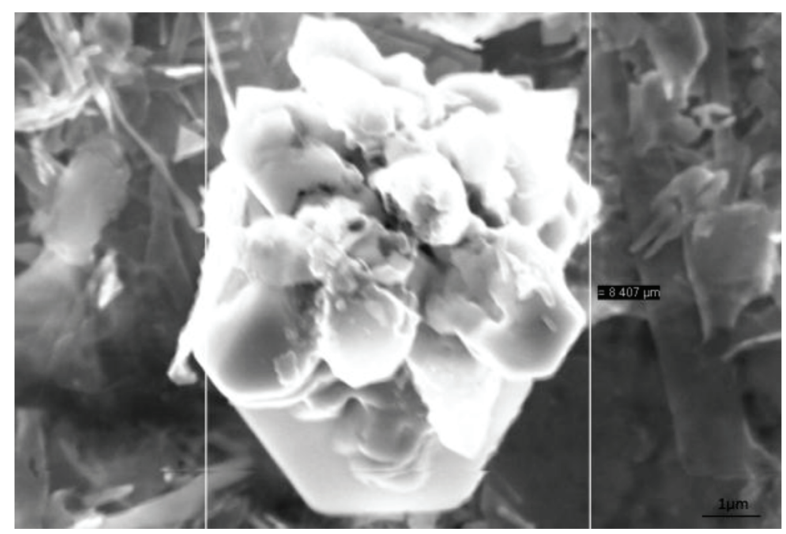

Figure 1. SEM image of actual BN cluster-like inclusions in steel.

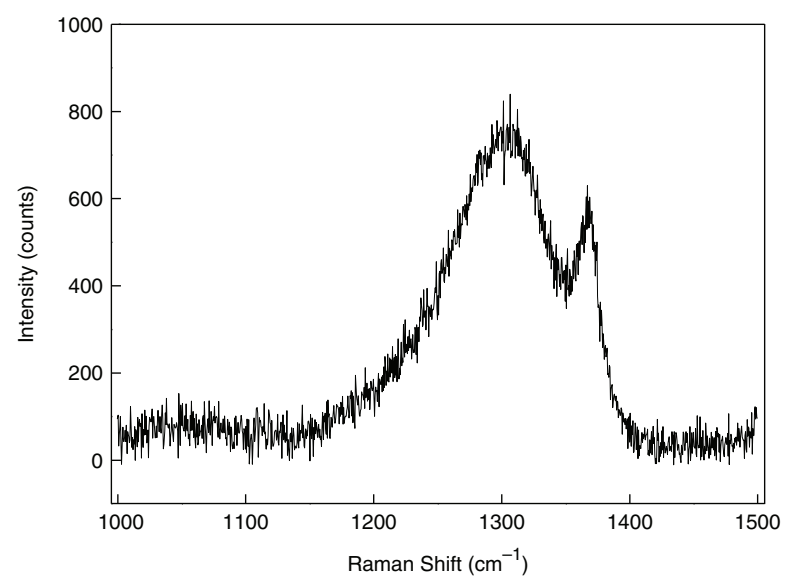

FIGURE 2. Raman spectra of BN inclusion participated in steel. ranged from 5 30 $\mu \mathrm{m}$, shown in Figure 1. The BN participated in the steel is analyzed by Raman spectroscopy. The result (Fig. 2) shows that Ramanactive high-energy phonon is at $1367 \mathrm{~cm}^{-1}$, which agrees well with the pure hexagonal boron nitride (Reich et al., 2005), which has the same hexagonal crystal structure and lubrication action as graphite, and is opposite with super hard cubic BN.

\subsection{The distribution of $\mathrm{BN}$ inclusions}

Cluster-like BN inclusions distribute uniformly in experimental samples, as shown in Figure 3. The $3 \mathrm{D}$ sketch of $\mathrm{BN}$ inclusions is shown in Figure 4. Six metallographic specimens were taken from different positions of the ingot in order to count and analyze the inclusions in sample as accurate as possible. The amount of $\mathrm{BN}$ inclusions was counted and the distribution was quantitatively analyzed by optical microscope $(400 \times)$ with 100 view fields of each specimen collected. According to statistic data, the average diameter of $\mathrm{BN}$ inclusions is $16.8 \mu \mathrm{m}$, the average number is 23.2 per unit area and the area ratio is $0.507 \%$ in $\mathrm{C} 45 \mathrm{BN}$ sample with $74 \mathrm{ppm}$ $\mathrm{B}$ and $180 \mathrm{ppm} \mathrm{N}$, as shown in Table 3 .

\subsection{The improved machinability of $\mathrm{BN}$ added steel}

The hardness of samples, including cast samples and forged samples, are compared in Table 4. The hardness of cast C45 and C45BN samples is 199.8 and 190.3 respectively, while the hardness of forged $\mathrm{C} 45$ and $\mathrm{C} 45 \mathrm{BN}$ samples is 225 and 220 respectively, which shows that the hardness of samples in the same condition is almost the same level. Based on the hardness results, different modes and materials of cutting were chosen to investigate the effects of $\mathrm{BN}$ inclusions on machinability of steel. Figures 5-7 show the relationship between the average width of flank wear and cutting length in cast and forged samples, if the rotational speed (RS) is $2100 \mathrm{r} \mathrm{min}^{-1}$ and $560 \mathrm{r} \mathrm{min}^{-1}$, separately. Table 5 shows the tool life during cutting different materials in different modes.

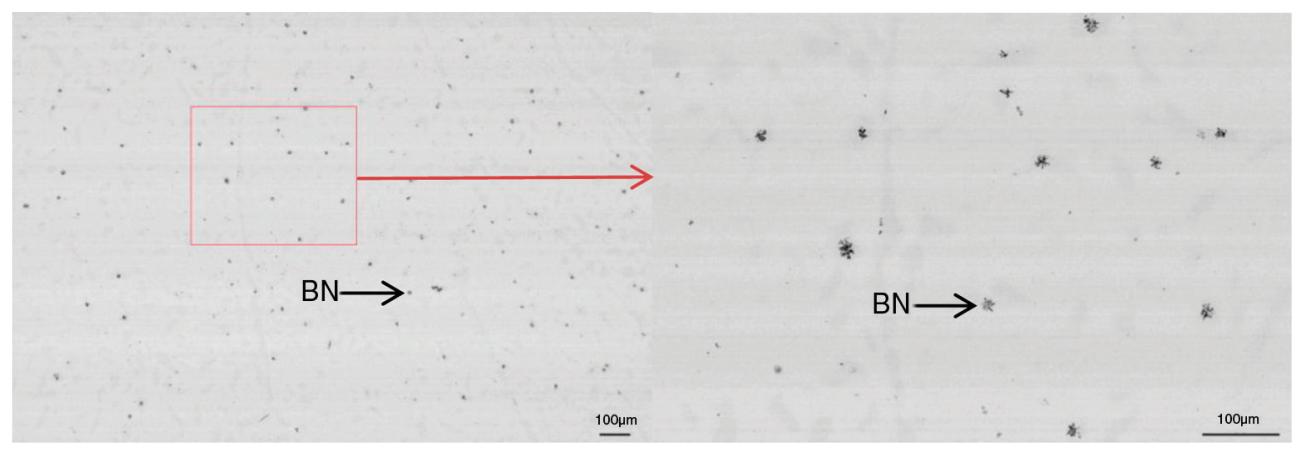

FIGURE 3. Distribution of $\mathrm{BN}$ inclusions in $\mathrm{C} 45 \mathrm{BN}$ sample. 


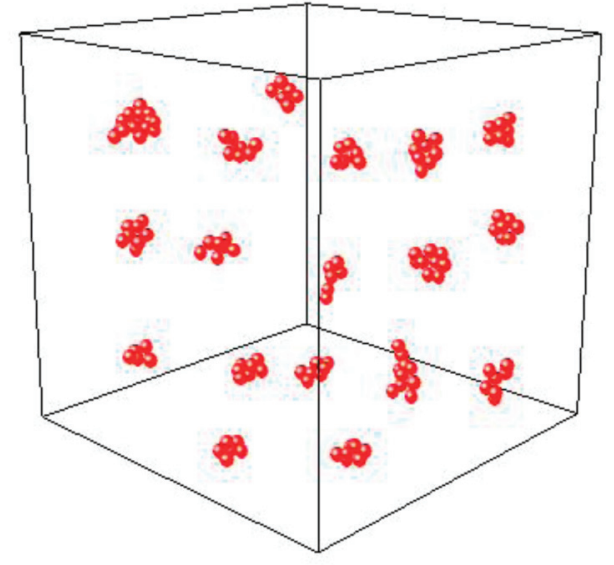

FIGURE 4. Schematic 3D sketch of BN inclusions in C45BN sample.

TABLE 3. The average diameter, average number per unit area and the area ratio of $\mathrm{BN}$ inclusions in $\mathrm{C} 45 \mathrm{BN}$ sample

\begin{tabular}{ccccc}
\hline Sample & Inclusion & $\begin{array}{c}\text { Average } \\
\text { diameter }(\boldsymbol{\mu m})\end{array}$ & $\begin{array}{c}\text { Average } \\
\text { number }\left(\mathbf{m m}^{2}\right)\end{array}$ & $\begin{array}{c}\text { Area } \\
\text { ratio }(\%)\end{array}$ \\
\hline C45BN & BN & 16.8 & 23.2 & 0.507 \\
\hline
\end{tabular}

TABLE 4. Samples hardness

\begin{tabular}{lcc}
\hline Sample & $\begin{array}{c}\text { Hardness (cast) } \\
\text { (HV0.5) }\end{array}$ & $\begin{array}{c}\text { Hardness (Forged) } \\
\text { (HV0.5) }\end{array}$ \\
\hline C45 & 199.8 & 225 \\
C45BN & 190.3 & 220 \\
\hline
\end{tabular}

It can be seen from above results that $\mathrm{BN}$ inclusions can improve the cutting performance of steel significantly. According to Figure 7, the average

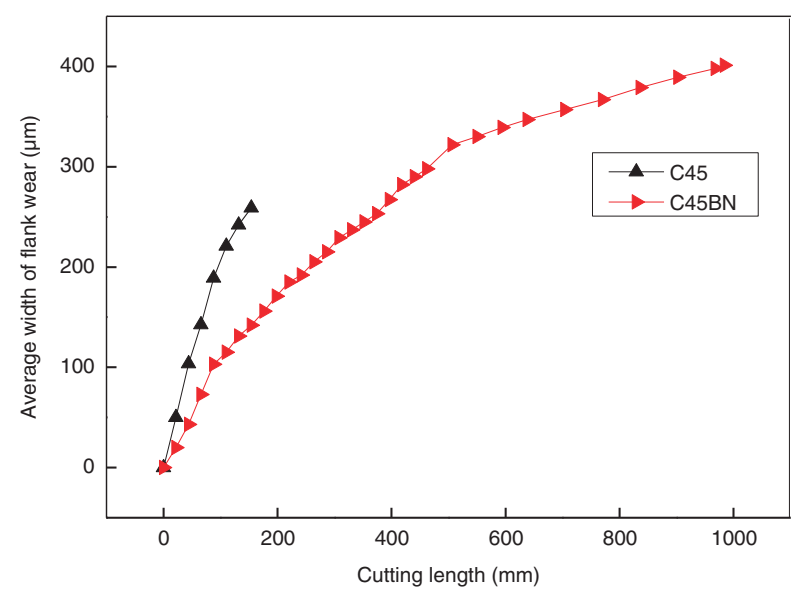

FIGURE 5. Relationship between the average width of flank wear and cutting length in cast samples (RS: $2100 \mathrm{r} \cdot \mathrm{min}^{-1}$ ).

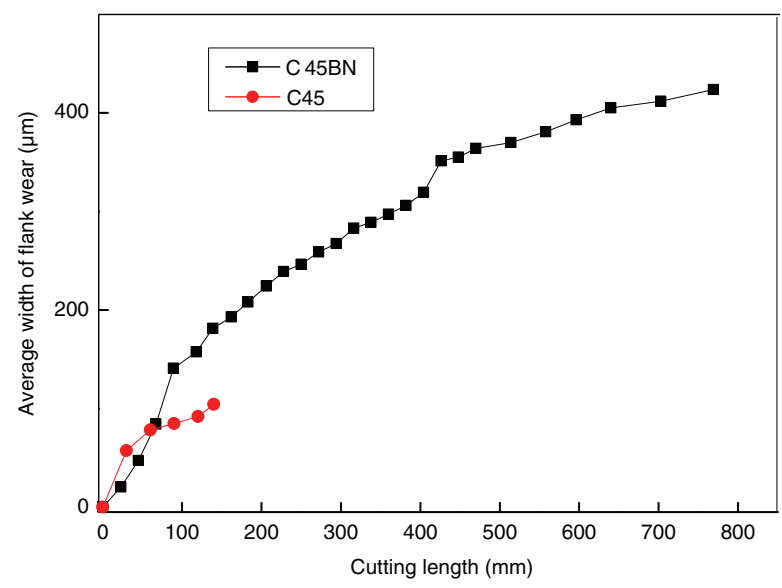

FIGURE 6. Relationship between the average width of flank wear and cutting length in forged samples (RS: $2100 \mathrm{r} \cdot \mathrm{min}^{-1}$ ).

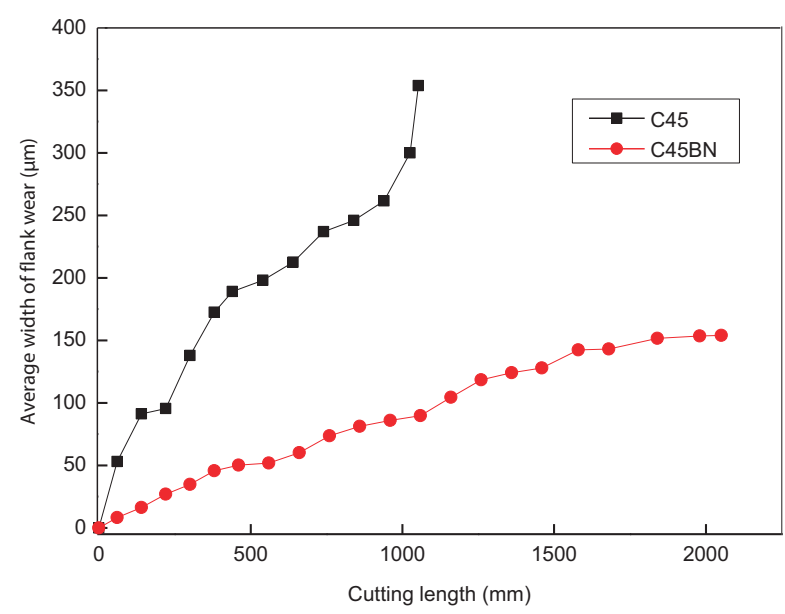

FIGURE 7. Relationship between the average width of flank wear and cutting length in forged samples (RS: $560 \mathrm{r} \cdot \mathrm{min}^{-1}$ ).

width of flank wear is only $154 \mu \mathrm{m}$ with $2051 \mathrm{~mm}$ cutting length in forged C45BN sample, while the average width of flank wear is reach up to $354 \mu \mathrm{m}$ with only $1053 \mathrm{~mm}$ cutting length in forged C45 sample. The tool wear in cutting $\mathrm{BN}$ added steel is less than half of that in cutting the compared steel while the cutting length of BN added steel is twice than that of compared steel. Especially, if forged samples were cut in high rotational speed,

TABLE 5. Cutting tool life

\begin{tabular}{llclr}
\hline RS & Sample & $\begin{array}{c}\text { Tool life } \\
(\mathbf{m i n})\end{array}$ & \multicolumn{1}{c}{ Sample } & $\begin{array}{c}\text { Tool life } \\
(\mathbf{m i n})\end{array}$ \\
\hline $2100 \mathrm{r} \cdot \mathrm{min}^{-1}$ & Cast C45 & 3.8 & Cast C45BN & 24.6 \\
& Forged C45 & 3.5 & Forged C45BN & 19 \\
$560{\mathrm{r} \cdot \mathrm{min}^{-1}}^{-1}$ & Forged C45 & 70 & Forged C45BN & 137 \\
\hline
\end{tabular}


TABLE 6. Nanoindentation characterization results

\begin{tabular}{llcccc}
\hline Sample & Inclusion & Hardness (GPa) & Modulus of elasticity (GPa) & Maximum load (mN) & Maximum displacement (nm) \\
\hline $\mathrm{C} 45 \mathrm{BN}$ & $\mathrm{BN}$ & 1.658 & 132.83 & 9.96 & 519.058 \\
& $\mathrm{MnS}$ & 2.405 & 210.179 & 14.88 & 517.031 \\
& $\mathrm{Al}_{2} \mathrm{O}_{3}$ & 3.928 & 239.072 & 27.836 & 506.951 \\
& $\mathrm{TiN}$ & 12.603 & 307.347 & 76.872 & 518.126 \\
& Base Metal & 4.456 & 244.074 & 25.30 & 517.168 \\
\hline
\end{tabular}

$\mathrm{BN}$ inclusions have the most obvious effect on machinability of steel. The tool life of the cutting forged C45BN steel at $2100 \mathrm{r} \mathrm{min}^{-1}$ is about 19 minutes, which is almost 5.4 times as long as the other grade at the same condition. Generally speaking, the tool flank wear can be reduced remarkably at low speed cutting and the service life of a tool can be prolonged noticeably at high speed cutting of $\mathrm{BN}$ added steel.

\subsection{The cutting mechanism model of $\mathrm{BN}$ inclusions}

Based on the theory analysis and experiments, the cutting mechanism model of $\mathrm{BN}$ inclusions was proposed.

\subsubsection{Stress concentration source}

The micro mechanical properties of the matrix and the inclusions in sample were investigated by nanoindentation method. As can be seen from the nanoindentation characterization results (Table 6), the hardness of $\mathrm{BN}$ is the lowest in comparison to base metal, followed by $\mathrm{MnS}, \mathrm{Al}_{2} \mathrm{O}_{3}$, and TiN. The hardness of TiN is greater than the base metal. Accordingly, BN inclusions can destroy the matrix continuity and play the role of internal gap in matrix due to its low hardness, just as the 3D sketch of $\mathrm{BN}$ inclusions in matrix shown in Figure 4. Because of this, stress concentration will be caused in the cutting process and then the cutting force will be reduced.

\subsubsection{Lubrication}

Table 7 shows the plastic deformation of inclusions in samples, which are obtained by the loaddisplacement curve (nanoindentation experiments results). The value of $\mathrm{BN}$ plastic deformation

TABLE 7. Inclusion plastic deformation

\begin{tabular}{lccccc}
\hline Inclusion & $\mathbf{B N}$ & $\mathbf{M n S}$ & $\mathbf{A l}_{2} \mathbf{O}_{3}$ & $\mathbf{T i N}$ & $\begin{array}{c}\text { Base } \\
\text { Metal }\end{array}$ \\
\hline $\begin{array}{l}\text { Unit plastic } \\
\text { deformation }\left(\mathrm{nm} \mathrm{mN}^{-1}\right)\end{array}$ & 40.16 & 32.19 & 15.80 & 4.52 & 17.67 \\
\hline
\end{tabular}

is the largest, and the second is $\mathrm{MnS}$, both are larger than the base metal and $\mathrm{Al}_{2} \mathrm{O}_{3}$. And TiN has the smallest plastic deformation, relatively. Accordingly, BN inclusions, just like as $\mathrm{MnS}$ inclusions, have a good plastic deformation capacity. In addition, BN added steel was cut by high speed steel drill, elements $\mathrm{B}$ and $\mathrm{N}$ were found attached on the surface of the cutting tool, as shown in Figure 8.

The presented results show that $\mathrm{BN}$ inclusions soften and adhere the tool rake face in the cutting process, participating in the plastic flow of rheological layer in tool-chip contact region. The toolchip friction and the cutting force can be reduced. Consequently, BN inclusions have an effective internal lubrication in the chip shear region and the deformation flow layer, as well as lubrication between the chip and the tool.

\subsubsection{Wrappage of hard particles}

Some compound BN inclusions were observed in $\mathrm{C} 45 \mathrm{BN}$ sample. As shown in Figure 9, hard particles, such as $\mathrm{Al}_{2} \mathrm{O}_{3}, \mathrm{SiO}_{2}$, were wrapped by $\mathrm{BN}$. The direct contact of cutting tool and hard particles will be avoided in the cutting process, thus wear of hard inclusion on cutting tool can be reduced and then steel cutting performance can be improved.

\section{CONCLUSIONS}

The $\mathrm{BN}$ participated in steel is $\mathrm{h}-\mathrm{BN}$. The $\mathrm{BN}$ inclusions distribute uniformly, the average number is 23.2 per unit area and the area ratio is $0.507 \%$ in steel with $74 \mathrm{ppm} \mathrm{B}$ and $180 \mathrm{ppm}$ N.

$\mathrm{BN}$ inclusions can improve the cutting performance of steel significantly. The flank wear can be reduced remarkably at low speed cutting and cutting tool life can be extended noticeably at high speed cutting in BN added steel.

The cutting mechanism model of $\mathrm{BN}$ inclusions is proposed in the paper. $\mathrm{BN}$ inclusions have the effects of stress concentration source, lubrication and wrappage of hard particles, which improve the cutting performance of steel greatly. 


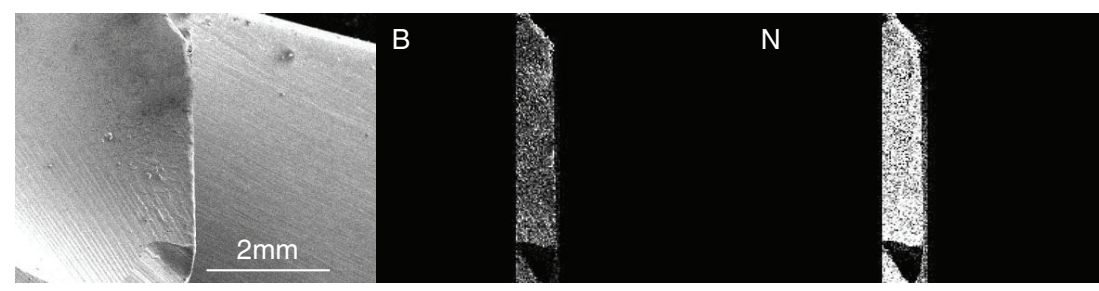

FIGURE 8. Element distribution of tool rake face.
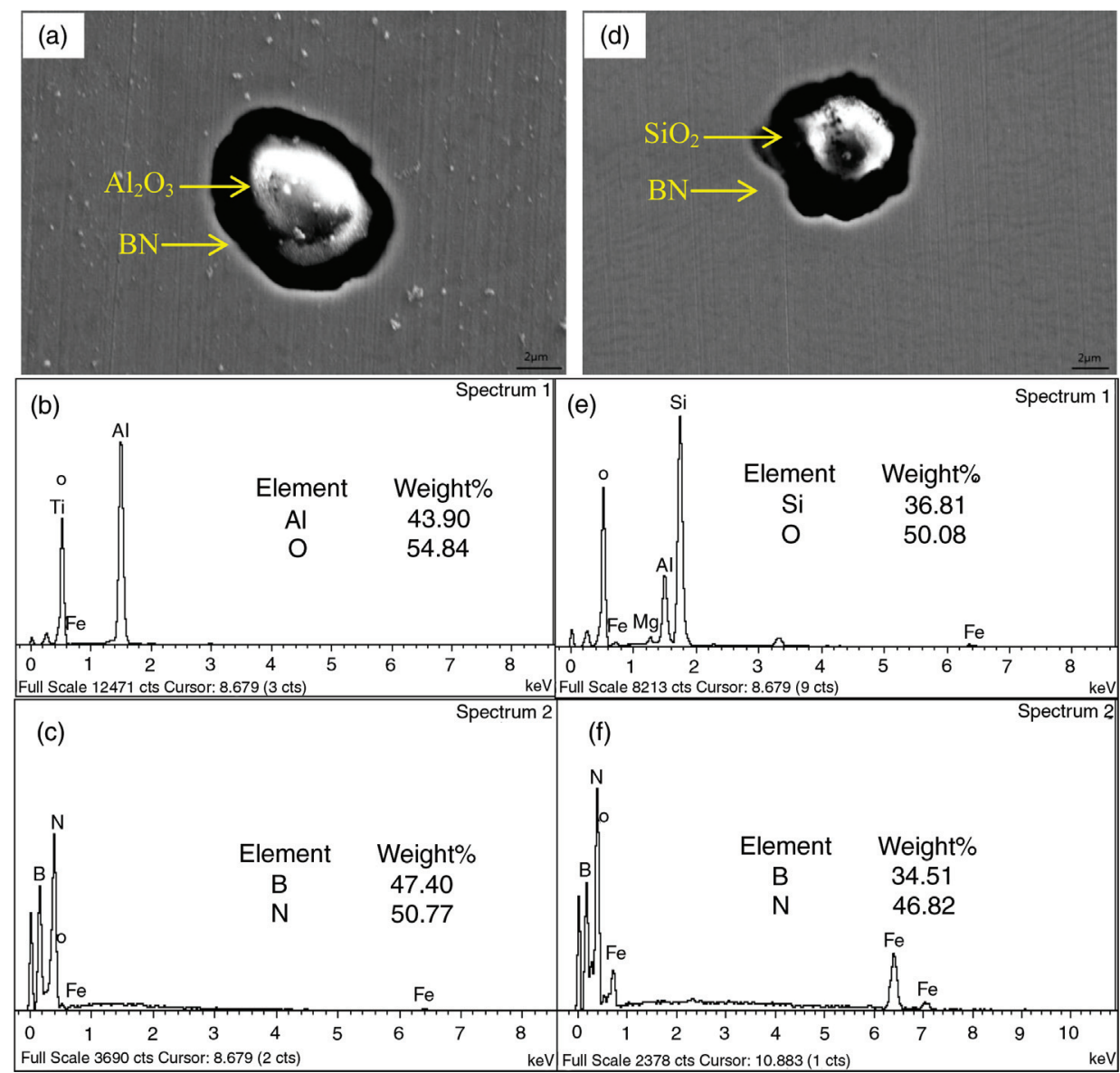

FIGURE 9. SEM images of compound $\mathrm{BN}$ inclusions and the EDS analysis : (a) shows $\mathrm{SEM}$ image of $\mathrm{BN}^{-\mathrm{Al}_{2} \mathrm{O}_{3}}$ compound inclusion; (b) and (c) show the EDS analysis of the $\mathrm{BN}-\mathrm{Al}_{2} \mathrm{O}_{3}$ inclusion; (d) shows $\mathrm{SEM}$ image of $\mathrm{BN}-\mathrm{SiO}_{2}$ compound inclusion; (e) and (f) show the EDS analysis of the $\mathrm{BN}-\mathrm{SiO}_{2}$ inclusion.

\section{ACKNOWLEDGEMENTS}

This research was financially supported by the National Natural Science Foundation of China $\left(\mathrm{N}^{\circ}\right.$ 51274029), China Postdoctoral Science Foundation $\left(\mathrm{N}^{\circ} 2012 \mathrm{M} 510319\right)$ and State Key Laboratory of Advanced Metallurgy Foundation ( $\left.\mathrm{N}^{\circ} 41602014\right)$.

\section{REFERENCES}

Bao, Y.P., Wang, M. Jiang, W. (2012). A method for observing the three-dimensional morphologies of inclusions in steel. Int. J. Miner. Metall. Mater. 19 (9), 111-115. http://dx.doi. org/10.1007/s12613-012-0524-3.
Chen, M., Liu, G., Zhang, X.H., Shen, Z., Yang, G.J. (2007). Experiment on machinability of new developed low carbon sulphur free-cutting steel. Chin. J. Mech. Eng. 43 (9), 161-166.

Emura, S., Yamamoto, S., Sakuraya, K., Tsuzak1, K. (2012). Free-cutting stainless-steel cast product and process for producing same, European Patent, EP 2537952.

Emura, S., Yamamoto, S., Sakuraya, K., Tsuzakl, K. (2013). Free-cutting stainless-steel material for precision processing and process for producing same. European Patent, EP 2565286.

Katayama, S., Imai, T., Onodera, N., Ishibashi, Y. (1988). Continuous-cast low-carbon resulfurized free-cutting steel, Patent US4719079, USA.

Liu, H.T., Chen, W.Q. (2014). Hot ductility of eco-friendly low carbon resulphurised free cutting steel with bismuth. Ironmak. Steelmak. 41 (1), 19-25. http://dx.doi.org/10.1179/17 43281212 Y.0000000095. 
Reich, S., Ferrari, A.C., Arenal, R., Loiseau, A., Bello, I., Robertson, J. (2005). Resonant Raman scattering in cubic and hexagonal boron nitride. Phys. Rev. B. 71, 205201-1205201-12. http://dx.doi.org/10.1103/PhysRevB.71.205201.

Sakuraya, K., Okada, H., Abe, F. (2006). Influence of heat treatment on formation behavior of boron nitride inclusions in P122 heat resistant steel. ISIJ Int. 46 (11), 1712-1719. http://dx.doi.org/10.2355/isijinternational.46.1712.

Spitzig, W.A. (1983). Effect of sulfides and sulfide morphology on anisotropy of tensile ductility and toughness of hotrolled C-Mn steels. Metall. Trans. A. 14 (2), 471-484. http://dx.doi.org/10.1007/BF02644224.

Spitzig, W.A., Sober, R.J. (1981). Influence of sulfide inclusions and pearlite content on the mechanical properties of hotrolled carbon steels. Metall. Trans. A. 12 (2), 281-291. http://dx.doi.org/10.1007/BF02655201.

Tanaka, R., Yamane, Y., Sekiya, K., Narutaki, N., Shiraga, T. (2007). Machinability of BN free-machining steel in turning. Int. J. Mach. Tool. Manuf. 47 (12-13), 1971-1977. http://dx.doi.org/10.1016/j.ijmachtools.2007.02.003.

Tanaka, R., Lin, Y., Hosokawa, A., Ueda, T., Yamada, K. (2009). Influence of additional electrical current on machinability of BN free-machining steel in turning. J. Adv. Mech. Des.
Syst. Manuf. 3 (2), 171-178. http://dx.doi.org/10.1299/ jamdsm.3.171.

Wang, Y.N., Bao, Y.P., Wang, M., Zhang, L.C. (2013a). Precipitation behavior of BN type inclusions in 42CrMo steel. Int. J. Miner. Metall. Mater. 20 (1), 28-36. http://dx.doi.org/ doi:10.1007/s12613-013-0689-4.

Wang, Y.N., Bao, Y.P., Wang, M., Zhang, L.C., Chen, Y.N. (2013b). Basic research on precipitation and control of BN inclusions in steel. Metall. Mater. Trans. B. 44 (5), 1144-1154. http://dx.doi.org/doi:10.1007/s11663-013-9881-1.

Wang, Y.N., Bao, Y., Wang, P.M., Zhang, L.C. (2013c). Precipitation and control of $\mathrm{BN}$ inclusions in $42 \mathrm{CrMo}$ steel and their effect on machinability. Int. J. Miner. Metall. Mater. 20 (9), 842-849. http://dx.doi.org/doi:10.1007/ s12613-013-0805-5.

Yamamoto, K. Yamamura, H., Suwa, Y. (2011). Behavior of non-metallic inclusions in steel during hot deformation and the effects of deformed inclusions on local ductility. ISIJ Int. 51 (12), 1987-1994. http://dx.doi.org/10.2355/ isijinternational.51.1987.

Yoshimura, T. (1985). Method of Manufacturing Leaded FreeCutting Steel by Continuous Casting Process, Patent US4524819. USA. 